\title{
Systems thinking in construction: Improving the productivity and performance of infrastructure projects
}

(C) The Author(s) 2018. Published by Higher Education Press. This is an open access article under the CC BY license (http:// creativecommons.org/licenses/by/4.0)

"Systems thinking is a discipline for seeing wholes. It is a framework for seeing interrelationships rather than things, for seeing patterns of change, rather than static snapshots" (Peter Senge).

Investment in infrastructure is required to meet the growing needs of an increasing population, as well as to sustain a competitive advantage in the global marketplace. For an economy to position itself to capitalize on growth and increased investment due to a burgeoning population and increasing international demand for goods and services, greater investment in infrastructure is needed. Yet history explicitly indicates the capital expenditure (CAPEX) of infrastructure projects routinely overrun their initial cost estimates leaving asset owners, financiers, contractors and the public dissatisfied; the productivity and profitability of organizations are also adversely impacted. This is not an unusual situation for infrastructure projects, as it has been observed that on average, $48 \%$ of them fail to meet their baseline time, cost and quality objectives. Well-known infrastructure projects that have attracted the attention of the popular press due to cost overruns being incurred include Boston's Big Dig, the Denver International Airport, and the Øresund Bridge linking Denmark to Sweden.

If the CAPEX of a project overruns, then the scope of works in others being considered or undertaken by Government's may be reduced to accommodate the increased expenditure. Moreover, contractors could face cash flow issues, liquidity and damage to their business image while the public has to pay more when the taxpayer funds projects. This may also have a knock-on effect on the funds available for maintaining and operating the asset. For Governments, managing the cost performance of their portfolio of infrastructure projects is essential for ensuring the economic competitiveness and wealth for its constituents; it is a critical metric, as it quantifies the cost efficiency of the work completed. Cost performance is generally defined as the value of the work completed compared to the actual cost or progress made on the project. Thus, the ability to reliably estimate the final cost of construction is vital for maintaining the planning and resourcing in other projects or those in the pipeline. An issue that has been overlooked is the cost overrun that often materializes during the operation and maintenance of the asset that is constructed. Often infrastructure projects are delivered using Public Private Partnerships or variants thereof, though during operations and maintenance the private sector will generally be responsible for managing the asset.

Despite the considerable amount of research that has been undertaken, the performance of infrastructure projects remains a problem for Governments worldwide. While studies have provided the essential building blocks to understand and provide a much-needed stimulus for theory that can be used to explain the poor performance of infrastructure projects, they are still prone to cost and schedule overruns and subjected to poor productivity. Understanding infrastructure projects by examining their linkages and interactions between their components can provide the impetus for developing strategies to improve their performance.

In making headway to better understand how we can improve the performance and productivity of infrastructure projects at International Workshop entitled "Systems Thinking in Construction" was organized by Huazhong University of Science and Technology in collaboration with the Frontiers of Engineering Management (FEM) from 5th-7th in December 2017 in Wuhan, China. Key challenges, new ideas, technologies and methods to address the issues confronting our ability to design, manage, construct, operate and maintain infrastructure assets were presented and discussed with particular emphasis being placed on 'systems thinking.'

Received July 23, 2018 
It is through the lens of systems thinking that we are able to better understand the interrelationships between people, organizations, technology and the environment within which infrastructure projects are procured. The workshop provided a forum for robust discussion, and the through the lens of 'system thinking' a platform for better understanding the problems that typically confront construction was provided. People make mistakes, but more often than not it is the organization and the work environment that has been established that contributes to problems materializing in construction. W. Edwards Deming (1900-1993), for example, observed that "94\% of problems in business are systems driven, and 6\% are people driven". In addition, Deming stated, "every system is perfectly designed to get the results it gets." If we are to make inroads to improving the procurement of infrastructure and enable assets to be future-proofed, then we need to make 'changes' to the way we do things in construction. While it has been recognized by Governments and practitioners, worldwide, for several decades that such change is needed, we have fallen short in our willingness to understand the underlying nature of the problems that confront the practice of construction. Solutions and strategies that have been developed have not been able to provide the desired productivity and performance improvements sought. This point is explicitly articulated in the commentary presented by Love et al. in this special issue.

We have selected a number of papers that were presented at the workshop for inclusion in this special issue. The papers address a diverse range of themes and problems that materialize in construction. This special issue commences with a paper entitled "Conceptualising the nexus of projects, finance and the capacity in construction business" by Bajracharya et al. who aim to understand why construction companies fail in their business. Building upon the previous knowledge that embraces the concept of growth and capacity underinvestment archetype, a new and operational model grounded in systems thinking is introduced. The developed model examines various modes of business performance of small and medium construction companies. The model is comprised of three components (projects, finance and capacity), which are used to understand the inter-relationships between them. Understanding the relationship and dynamics between these components forms the crux for forming strategies and policies to lift profitability of construction businesses.

A technologically enabled solution that has been identified for engendering change in construction is Building Information Modeling (BIM). But despite its potential, the organisational and contractual frameworks that are being used to deliver BIM projects only partially support collaboration throughout a project's life. Collaboration can occur at many levels and take many guises within a BIM environment. Enacting collaborative changes in a BIM data repository in a multi-model environment, for example, is a challenge. In the paper entitled "Model server enabled management of collaborative changes in building information models" Shafiq et al. recognize this challenge and have suggested that managing iterative changes in BIMs is a database problem, which is exacerbated by the long transaction times needed to support collaborative design progression. But, this is a problem that has yet to be resolved in the construction and better solutions are needed to support the underlying workflows and computing operations for seamless collaboration on BIMs. In addressing this issue, Shafiq et al. propose the use of the structural and semantic characteristics of BIM objects as a mechanism for tracking changes across co-developed solutions. The creation of object signatures, using hash codes derived from their characteristics, provides a potential mechanism for object comparison and effective change recognition and management.

Resilience and adaptiveness are innate features of future-proofing. The concept of resilience, however, brings together disaster and climate risks. The widely accepted United Nations definition of resilience "is the ability of a system, community or society exposed to hazards to resist, absorb, accommodate to and recover from the effects of a hazard in a timely and efficient manner, including through the preservation and restoration of its essential basic structures and functions" (UN, 2015). In the paper entitled "Attributes, challenges and future directions of community resilience" Meng et al. recognize the importance of communities to utilize available resources to respond to, withstand, and recover from adverse conditions. Meng et al. apply database retrieval to untangle community resilience-related papers from multiple directions by determining the attributes, challenges and future directions of community resilience. Meng et al. suggest that the development of future community resilience should take a "system of system" perspective and build on knowledge and tools of various relevant domains. Moreover, it is preffered that future research should integrate infrastructure and economic resilience, social resource allocation, network connection, and other aspects to build a holistic and functional resilient community.

In the paper entitled "Facility manager's perceptions on building performance" Bortolini and Forcada commence their study with the premise that during the operational phase, building performance decreases in several areas and therefore end users' requirements are no longer met. They suggest that there is a need for a series of indicators to be established that can be used to assess the existing performance of buildings. Drawing from the extant literature and conducting a series of focus groups with facility management experts a series of operational indicators are propagated. Key indicators for measuring a building's operational performance are revealed to be safety and assets working properly, health and comfort, space functionality, and energy performance. In addition, Bortolini and 
Forcada found that these indicators can be obtained from three primary sources: (1) facility managers/operators, who carry out corrective maintenance and perform technical inspections; (2) regular users, who report complaints and fill-in satisfaction questionnaires; and (3) sporadic users, who also fill-in satisfaction questionnaires. The indicators and their sources can contribute to a better analysis of building performance during the operational phase of a building.

Understanding why projects fail is an area of research that has received a considerable amount of interest, particularly mega-projects as they can be central to economic and social development. The Ajaokuta Steel plant located in Ajaokuta in Kogi State in Nigeria has not met its objectives. Olatunji draws on the history surrounding this mega-project to offer a viewpoint as to reasons why this project failed. The title of Olatunji's paper "Causations of failure in megaprojects: A case study of the Ajaokuta Steel Plant" is befitting to this special issue as series of changing macro-economic conditions, interrelationships with stakeholders, and the socio-political environments acted in unison to result in the federal government spending over $\$ 8$ billion on the moribund steel plant since its inception in 1979. Nearly 40 years on, the project has not achieved full completion. Olatunji provides readers with some insightful and meaningful observations as to why this project failed and incurred a $1400 \%$ cost overrun. While normative literature only recognizes project success in a definitive perspective, this study acts as a catalyst to better understand the nuances of failure.

After several failed attempts at privatization, the Nigerian Government took control of the Ajaokuta Steel Plant in 2016. While this is now a State-owned asset and with the China Civil Engineering Construction Company completing the Abuja-Kaduna Standard Gauge Railway and repairing the Itakpe-Ajaokuta railway consideration of a Public Private Partnership could be an option for consideration to secure funding. Insights into enabling sustainable PPPs and balancing multiple actors and societal requirements are addressed by Leviäkangas and his colleagues in their paper entitled "Sustainable public-private partnerships: Balancing the multi-actor ecosystem and societal requirements." An integrated model of a PPP project is introduced by Leviäkangas et al. and its implications for appraising and selecting projects is presented. The integrated model suggests that merely investing in economically viable PPPs is insufficient and that value is best obtained when they are also socially sustainable.

A central technique of the future-proofing process is life-cycle cost analysis (LCAA). For LCAA is to serve its intended purpose it is necessary to examine the interrelationship that exists with costs throughout a project's life. Nishanth et al.'s paper entitled "Floating production storage and offloading systems' cost and motion performance: A systems thinking application" utilizes systems thinking to balance the technical performance of Floating Production Storage and Offloading (FPSO) vessels with a range of issues such as whole-life costs, and fitness for purpose design specification that address technical motion. The adoption of a soft systems methodology (SSM) enabled Nishanth et al.'s to identify problem areas and assess the antecedents of life-cycle costing in relation to a FPSOs sub-component design alternatives. A parametric study was conducted by varying wave heights from $4-8 \mathrm{~m}$ to understand FPSO motion behavior in the presence of wind and current, as well as comparing the motions of turreted versus spread mooring design alternatives. The LCCA data generated was used to compare the cost of such different mooring options/hull conditions over 10 and 25-year periods. Systems thinking enabled Nishanth et al. to explain the interaction between factors that influence the choice of FPSO configurations in terms of motion and whole-life costs in waters off Australia and Malaysia.

Urquhart and Whyte's paper entitled "Rethinking the tendering frameworks of construction contractors in the context of a soft systems methodology approach" focuses on the internal tendering (ITP) processes of contractors, which has received limited attention in the extant literature due to issues of commercial sensitivity and confidentiality. In examining this sensitive subject area, Urquhart and Whyte conducted 20-five semi-structured interviews with purposely selected publicly and privately owned construction companies in Australia that had varying turnovers. Urquhart and Whyte observe that contractors are concerned about the negative effects of increasing corporate governance demands, with many stating that people involved are the most critical element to tendering success. A new way of presenting the ITP of contractors is assessed using SSM, which also considers human interactions. Urquhart and Whyte suggest that the use of SSM can provide contractors with the ability to re-structure their tendering activities in a more humanistic and less rigid procedural manner.

In the penultimate paper of this special issue Kumanayake and Luo focus on assessing lifecycle carbon emissions in buildings. A process-based life cycle assessment methodology for assessing carbon emissions of buildings, using a multi-storey reinforced concrete building in a Sri Lankan university is presented. Kumanayake and Luo assess the entire cradle-to-grave building life cycle and provide evidence that the operation and material production stages contributed to total carbon emissions by $63.22 \%$ and $31.59 \%$ respectively. It was also revealed Kumanayake and Luo that the main structural materials, concrete and reinforcement steel made up $61.91 \%$ of the total carbon emitted at the material production stage. The life cycle carbon emissions of the building were found to be $31.81 \mathrm{~kg} \mathrm{CO} / \mathrm{m}^{2} /$ year, which is comparable with the values obtained in similar studies. Based upon these findings Kumanayake and 
Luo provided recommend strategies for introducing energy efficiency measures into the building design and operation process. The research undertaken by Kumanayake and Luo is important as it's the first to undertake a life cycle carbon emissions assessment for a building in Sri Lanka and therefore aims to engender environmentallyfriendly and sustainable construction practices to be adopted.

In the final paper of this special issue, we introduce a review paper of BIM within the context of project management by Chan et al. The work presented in this paper was not presented at the workshop but has been included in this special issue as systems thinking is integral to realizing the benefits of BIM in project management. The paper by Chan and his colleagues provides a comprehensive review of BIM studies in the area of project management from 2005 to 2017 and it can be seen that systems thinking has been an overlooked line of inquiry.

The Guest-Editors would like to thank the Executive Editor-in-Chief, Professor Lieyun Ding and the Executive Deputy Editor-in-Chief, Professor Hongwei Wang of the FEM for their support and encouragement to undertake this special issue. We would also like to thank the authors, reviewers and Professors' Pekka Leviäkangas, Nuria Focarda and Giorgio Locatelli for their contributions. Finally, we would like to acknowledge the wonderful support provided by the FEM Editorial staff, in particular, Ms Yong Li.

\section{Guest Editors-in-Chief \\ Peter E.D. Love \\ Professor, Curtin University, Australia \\ E-mail: plove@inet.net.au}

\section{Hanbin Luo \\ Professor, Huazhong University of Science and Technology, China \\ E-mail: luohbcem@ @ust.edu.cn}

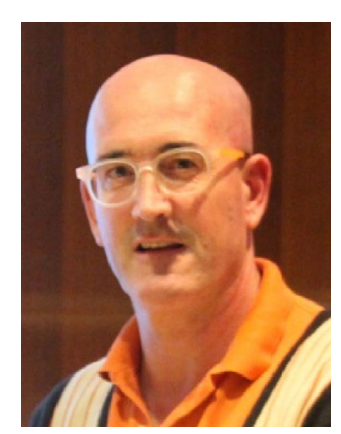

Prof. Peter Love is a John Curtin Distinguished Professor of Infrastructure and Engineering Informatics at Curtin University. He was a member of the inaugural Australian Research Council's Engineering and Environmental Science Panel 2010/11 Excellence in Australian Research Exercise and re-appointed for the 2018 evaluation process. Prof. Love's leadership in research and active engagement with the construction and resources industry was acknowledged in 2010 when he was awarded the inaugural Scopus Young Australian Researcher of the Year Award in 2010 and later in 2012 was a nominee for Australian of the Year. Prof. Love's impact reaches beyond academia via media engagements, policy advice to governments and multilateral institutions, and consulting with Fortune 500 companies. Prof. Love has co-authored/edited seven books and has authored/co-authored over 400 internationally refereed journal papers, which have appeared in leading international journals such as European Journal of Operations Research, IEEE Transaction on Engineering Management, International Journal of Production Economics, International Journal of Operations and Production Management, and Journal of Management Studies.

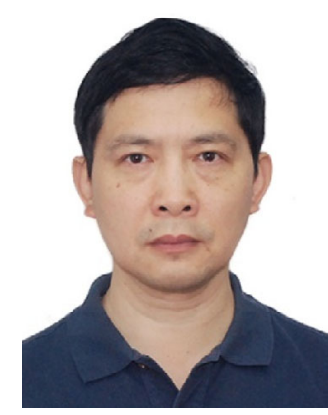

Prof. Hanbin Luo, is Professor of Construction Management, School of Civil Engineering and Mechanics, Huazhong University of Science and Technology. He is associate dean of School of Civil Engineering Mechanics; Director of Construction Management Department; Deputy Secretary General of Architectural Society of China-Construction Management Research Sector (CMRS-ASC); Secretary General of Architectural Society of China-Digital Construction Academic Committee (DCAS-ASC); Director of Center for Virtual, Safe \& Automated of Construction (ViSAC).

Prof. Luo has been working on the research of virtual, safe and automated construction. Prof. Luo has made outstanding achievements in the fields of safety risk identification, early warning and controlling in metro construction, and made great contribution to the improvement of safety performance in construction engineering in China. He has won the National Science and Technology Progress Award, 2nd Prize, the Science and Technology Progress Award of the Ministry of Education, 1st Prize, The Science and Technology Progress Award of Hubei Province, 1st Prize. Prof. Luo is the author or co-author of more than 100 scholarly publications. His research findings have been successfully applied in many metro and infrastructure construction projects in China. 